\title{
Aprendizagem por projeto e inovação tecnológica: união por competências
}

\author{
José Renato Cavalcanti Queiroz*; Maria de Fátima Jorge de Oliveira*; Dácio Michel da Cruz
} Souza**; Ana Loisa de Lima e Silva Araújo**; Maria Alice Pimentel Fuscella*

\section{RESUMO}

Metodologias ativas de ensino focadas em promover a integração dos agentes envolvidos podem fazer a diferença no processo de ensinoaprendizagem. Na Aprendizagem Baseada em Projeto (ABP), os estudantes mobilizam capacidades cognitivas e comportamentais, apresentando melhor evolução que os obtidos pela via tradicional de ensino onde há apenas transmissão de conhecimento. Este artigo vem relatar a experiência da Universidade Potiguar no uso desta metodologia, bem como os resultados apresentados em projetos de inovação tecnológica desenvolvidos ao longo de três anos.

Descritores: Educação Continuada em Odontologia. Educação em Odontologia. Avaliação. Metodologia.

\section{INTRODUÇÃO}

A autonomia na análise informacional e na inovação tecnológica integra as competências indicadas pelas Diretrizes Curriculares Nacionais no Brasil para graduandos em Odontologia ${ }^{1}$. Construir esta autonomia requer uma pedagogia que vença a passividade estudantil, quando o professor é o centro do processo educacional, para atingir a participação ativa na construção do seu conhecimento.

Embora a maioria dos procedimentos odontológicos requeiram habilidades predominantemente técnicas, a mobilização de competências cognitiva, sócio afetiva e psicomotora é necessária ao planejamento, uso de recursos e avaliação competente destes procedimentos. Adicionalmente, o conhecimento obtido na graduação será insuficiente para sustentar o profissional no mercado de trabalho em longo prazo, pela crescente evolução tecnológica, conceitual, material e filosófica das intervenções clínicas e promocionais individuais e ou coletivas.

A preparação para a atualização continua autocentrada com domínio de ferramentas da pesquisa científica no acesso a melhor evidência disponível e a detenção de fundamentos da epidemiologia, bioestatística e bioética, são indispensáveis. Inclui-se também a capacidade de reflexão crítica, interpretação de resultados e da correlação do conhecimento com as atividades profissionais.

Metodologias ativas de ensino focadas em fatores que promovem a integração do estudante, professor, método educacional e ambiente ${ }^{2}$ podem fazer a diferença no processo de ensinoaprendizagem. Na Aprendizagem Baseada em Projeto (ABP), os estudantes mobilizam capacidades cognitivas e comportamentais, onde o pensar e o fazer são contextos interligados mais valiosos que a instrução direta tradicional de apresentar conteúdo, o que provavelmente implica em melhoria do conhecimento. 
Mais recentemente, ocorrem esforços significativos para expandir a programação curricular proporcionando aos alunos uma exposição de base para processos de pesquisa e ao pensamento crítico, encorajamento à tomada de decisão baseada em evidências e estímulo ao interesse em carreiras de pesquisa acadêmica ${ }^{3}$.

Assim, o incentivo à inovação tecnológica, que necessariamente demanda a construção de um projeto guia formal, favorecerá a realização de experiências de investigação significativas envolvendo meto-dologia científica, bioética, conteúdos disciplinares diversos e orientação interdisciplinar. A definição clara de objetivos ajuda em muito a tomada de decisões, a reflexão sobre aspectos metodológicos, no saber o que se pretende fazer e na resolução em como proceder para se chegar aos resultados pretendidos. Trata-se de um processo que além do estímulo a competitividade, se concretiza numa organização que envolve as quatro formas de conversão do conhecimento: socialização no trabalho em equipe, combinação de métodos, técnicas, internalização e externalização do aprendizado, em um conjunto denominado como espiral do conhecimento ${ }^{4}$, o que certamente demonstrará sua utilidade pela aquisição das competências indicadas.

Neste contexto, se apresenta a experiência do Curso de Odontologia da Universidade Potiguar, utilizando a ABP no sentido de motivar os estudantes para a inovação tecnológica e implicações envolvidas no processo.

\section{RELATO DE EXPERIÊNCIA}

Desde 2012, o Curso de Odontologia da Universidade Potiguar vem utilizando a ABP, por meio de trabalho interdisciplinar envolvendo alunos do $3^{\circ}$ período do curso, em projetos de inovação tecnológica. Os estudantes são orientados no semestre a desenvolver produtos odontológicos, técnicas, equipamentos e protocolos de serviços, utilizando conhecimentos das ciências básicas, humanas e odontológicas, buscando a articulação entre os ciclos básico e clínico.

Inicialmente os alunos são aleatoriamente distribuídos em equipes, incentivando-se valores e atitudes como responsabilidade, ética e empatia. Cada equipe identifica um orientador que, necessariamente, é um professor de uma das Unidades Curriculares do $3^{\circ}$ período (Aspectos Biomoleculares do Sistema Estomatognático, Construção do Conhecimento e Metodologia da Pesquisa, Desenvolvimento Morfofuncional do Sistema Estomatognático, Mecanismo de Agressão e Defesa e Saúde Bucal Coletiva I). Sob a orientação de um manual próprio, seguem-se as seguintes etapas expostas no quadro 1 .

O manual contém instruções básicas do passo a passo a ser seguido para a construção de um projeto de inovação, contemplando desde a identificação do problema e geração da hipótese até o desenvolvimento do protótipo. Não há prévia seleção de temas para que haja o exercício da criatividade e o incentivo à investigação científica. Porém, há a orientação de que os temas abordados devem contemplar as unidades curriculares do terceiro período ou de períodos anteriores.

A disciplina de Metodologia Científica (80h/semestre) é responsável pelo suporte teórico na construção do Projeto de Inovação Tecnológica (PIT). O conteúdo das aulas é definido em função das necessidades requeridas para o projeto, oferecendo suporte em cada fase de sua execução. São trabalhados temas como o conhecimento e seus níveis, tipos de estudos, pesquisa em bancos de dados, pesquisa científica (natureza, objetivos, objeto, métodos e técnicas), definição do problema, objeto e tema, trabalhos acadêmicos (modalidades, estruturação e normalização), oficinas do projeto de inovação (orçamento e cronograma), ética na pesquisa científica, introdução à bioestatística, apresentação oral e escrita de trabalhos científicos, entre outros. Entretanto, cabe ao orientador de cada projeto coordenar a execução e avaliar a equipe. Na etapa das apresentações orais, cada equipe sugere três responsáveis pela apresentação, sendo que dois são definidos por sorteio no momento da exposição.

Oportunamente, os produtos são apresentados durante evento científico do curso, por meio 
de mesa demonstrativa e banners, uso de tecnologias de informação e, eventualmente, alguns podem seguir em aprofundamento como

projeto de pesquisa institucional e ou desenvolvimento de Trabalho de Conclusão de Curso.

Quadro 1. Etapas a serem seguidas na $\mathrm{ABP}$ que direcionam a realização do projeto de inovação tecnológica.

\begin{tabular}{|c|c|}
\hline ETAPAS & NORMALIZAÇÃO \\
\hline Definição do tema & Liberdade de escolha da ideia inovadora, criativa e prazerosa. \\
\hline $\begin{array}{l}\text { Descrição dos } \\
\text { objetivos }\end{array}$ & $\begin{array}{l}\text { Claros e viáveis com foco na obtenção dos resultados desejados e necessariamente } \\
\text { interdisciplinares. }\end{array}$ \\
\hline $\begin{array}{l}\text { Competências e } \\
\text { habilidades }\end{array}$ & Previstas nas ementas das Unidades Curriculares, incluindo as da formação geral. \\
\hline $\begin{array}{l}\text { Recursos } \\
\text { pedagógicos }\end{array}$ & $\begin{array}{l}\text { Aulas dialógicas, seminários, discussão em grupo, aulas práticas, pesquisa de campo e } \\
\text { problematização. }\end{array}$ \\
\hline Teorização & $\begin{array}{l}\text { Estudos e investigações sustentadas por literatura científica, integradora, desafiadora e } \\
\text { motivadora. }\end{array}$ \\
\hline Resumo temático & Em no máximo uma folha A4, letra Arial 12 e espaço simples. \\
\hline $\begin{array}{l}\text { Organização de } \\
\text { tarefas e atividades }\end{array}$ & $\begin{array}{l}\text { Primeiros passos, definição de tarefas, atividades, ações e encontros de orientações, com } \\
\text { apresentação de Cronograma e Orçamento em função dos prazos para apresentação e } \\
\text { avaliações e dos recursos requeridos sejam materiais, de equipamentos e infraestrutura } \\
\text { com avaliação crítica. }\end{array}$ \\
\hline Formação Geral & Assunção de posições de liderança, de trabalho em equipe e do aprender a aprender. \\
\hline Avaliação & $\begin{array}{l}\text { Contínua, verificando-se pontualidade, assiduidade e participação, relacionamento } \\
\text { interpessoal, desempenho nas atividades e cumprimento de prazos. Ao final, através de } \\
\text { relatório escrito e apresentação oral para banca examinadora, com critérios em Rubricas } \\
\text { de Avaliação incluindo domínios cognitivo, psicomotor e sócio afetivo. }\end{array}$ \\
\hline
\end{tabular}

A experiência é interdisciplinar, envolvendo as unidades curriculares relacionadas às Ciências Básicas, Saúde Bucal Coletiva e Metodologia Científica, com o conjunto de professores comprometidos e planejadamente integrados, evitando-se a fragmentação do conhecimento.

Em três anos de implantação do PIT, foram apresentados 50 novos recursos tecnológicos, cujo ponto de partida e de chegada é sempre a realidade social, num processo criativo de ação-reflexão sobre um determinado aspecto pesquisado, observado ou vivido. A lista de produtos inovadores criados inclui moldeira com passa fio dental para higiene bucal de pessoas com necessidades especiais; escova dental sustentável; aplicativos para telefones celulares, como é o caso do aplicativo Odontobaby, já disponível, com orientações sobre saúde bucal do bebê; produtos para tratamento de afta (Aftalima, Afta Protection) e herpes, para controle de placa, gengivite, mau hálito (Halit, Oral plus), hipersensibilidade dentinária (Alívio Gless Pro-Tec); escova educa- tiva (escova que interage com a criança durante a escovação); passador de fio dental para crianças (Line Floss kids); escova inteligente (Trimax escova, creme dental e fio dental juntos); cola cirúrgica (Colamagna); creme dental com extratos naturais; e estojo clínico/cirúrgico portátil para atendimento de pacientes em locais ermos.

Enquanto Metodologia Ativa (MA) a ABP associada ao PIT leva os alunos a exercitar habilidades e competências propostas para a formação profissional, através do trabalho em equipe, projetação e comprometimento. Eles também fazem a leitura de textos e artigos científicos, escrevem trabalhos, resumos e praticam a apresentação oral e escrita de trabalho científico.

\section{CONSIDERAÇÕES FINAIS}

A APB constitui-se em um método sistemático de ensino que envolve os estudantes na aquisição de conhecimentos, habilidades, valores e atitudes por meio de um processo de 
investigação estruturado, acompanhado e avaliado de forma processual ${ }^{8}$. Nesse sentido não dispensa o uso de metodologia científica.

É sabido a importância do envolvimento de alunos em pesquisa científica em sua própria evolução no processo educacional ${ }^{5}$ e em um possível envolvimento futuro com atividades acadêmicas e de docência ${ }^{3,6}$. O objetivo prioritário da APB/PIT é catalisar o desenvolvimento das competências de tomada de decisão, comunicação, administração e gerenciamento de situações complexas, liderança e educação permanente ${ }^{1,}$ associadas ao desafio da criatividade e competitividade.

A Lei da Inovação brasileira define a inovação como "introdução de novidade ou aperfeiçoamento no ambiente produtivo ou social que resulte em novos produtos, processos ou serviços"7. Assim, cada projeto do PIT deve buscar a criação de um produto de inovação tecnológica em Odontologia, ou seja, a exploração de novas ideias, identificando e solucionando problemas, bem como o descobrindo estratégias relacionadas à competitividade e à inclusão social, seja através de produtos, técnicas ou serviços, utilizando de forma articulada o conhecimento abordado até aquele momento do curso.

Pelo caráter inovador, os alunos se sentem desafiados e, naturalmente, surge à disputa sadia, fomentando a busca pelo melhor projeto. Os discentes aprendem a elaborar e apresentar trabalhos científicos, aplicar princípios de bioética, trabalhar em equipe de forma cooperativa e exercer tanto a liderança como a gestão dos recursos que serão empregados na geração do produto final do PIT.

Os professores orientadores mediam o suporte para as atividades de elaboração dos projetos enquanto MA, de forma que os alunos desenvolvam as habilidades de tradução (convertendo informações na geração de conhecimento) síntese (resumindo); busca e seleção crítica do conhecimento científico ${ }^{8}$ associadas ao conhecimento já adquirido nas ciências básicas, utilizando o PIT para aprender a aprender com autonomia e liberdade de escolha desde o nascedouro da ideia inovadora.

A MA é uma concepção educativa que estimula processos de ensino-aprendizagem crítico-reflexivos, no qual o educando participa e se compromete com seu aprendizado 9 . Sabe-se também que as metodologias ativas de ensino aprendizagem favorecem a participação dos estudantes de forma colaborativa demonstrando importância na aquisição de competências préprofissionais ${ }^{10}$.

Outras habilidades associadas são o exercício da criatividade (desenvolvendo novos produtos e buscando soluções também inovadoras); fala (persuasão, expor em público e debater); apresentação (planejamento e realização de apresentações orais), escrita (redigir de forma técnica e expositiva); uso de tecnologias de informação (uso de aplicativos, editoração eletrônica, planilhas e ilustrações), adaptação e curiosidade gerando produtos relevantes e de alta qualidade com responsabilidade pessoal e social.

A associação das ciências básicas com a racionalização e incorporação de novas informações, pela entrada no universo da pesquisa e da literatura científica, permite um aproveitamento acadêmico com a previsão de envolvimento do aluno em atividades acadêmicas durante o restante do curso, seja em pesquisa ou na extensão universitária.

Este ensino pautado na prática interdisciplinar pretende formar alunos com uma visão global de mundo, aptos para "articular, religar, contextualizar", situar-se num contexto e, se possível, globalizar a união dos conhecimentos adquiridos ${ }^{11}$.

Nesse sentido, em cada tema proposto, o projeto desenhado é comum às quatro unidades curriculares que compartilham assim o mesmo universo de construção.

Em conclusão, a experiência da ABP em união com um projeto de inovação tecnológica possibilita a estruturação de competências, habilidades, valores e atitudes que aproximam os alunos da aplicabilidade do conhecimento e 
manejo adequado deste saber na organização de soluções, mesmo que hipotéticas.

Ocorre reflexão sobre os problemas geradores de curiosidade e desafios, passando pela organização de recursos em busca de soluções. Eles constroem, assim, uma ponte com a realidade, germinando a corres-ponsabilidade e a independência na construção do saber em estado de permanente atualização. As atividades de inovação tecnológica realizadas na graduação em saúde estimulam e ampliam a capacidade criativa e gerencial dos alunos, gratificando também os professores no compartilhamento do sucesso alcançado.

\section{ABSTRACT \\ Project-based learning and technological innovation: integration by skills.}

Active teaching methodologies with focus to promote the integration of stakeholders can make a difference in teaching-learning process. In the Project Based Learning (PBL), students mobilize cognitive and behavioral skills, presenting better evolution than obtain using traditional way of teach that only transfer knowledgement. This article report the Potiguar University background in the use of PBL as well as the results presented as technological innovation projects developed over three years.

Descriptors: Education, Dental, Continuing. Education, Dental. Evaluation. Methodology.

\section{REFERÊNCIAS}

1. Ministério da Educação. Resolução CNE/CSE N. 3/2002: Diretrizes Curriculares Nacionais do Curso de Odontologia. Brasília: Diário Oficial da União, 2002, seção 1. [Acesso em 03/10/2014]. Disponível em: http://portal. mec.gov.br/cne/arquivos/pdf/CES032002.pdf

2. Hendricson WD. Changes in educational methodologies in predoctoral dental education: finding the perfect intersection. $\mathbf{J}$ Dent Educ 2012; 76 (1):118-41.

3. Scott JE, Vries J, Iacopino AM. 25-year analysis of a dental undergraduate research training program (BSc Dent) at the University of Manitoba Faculty of Dentistry. J Dent Res
2008; 87(12):1085-8.

4. Akeuchi H, Nonaka I. Gestão do conhecimento. Porto Alegre: Bookman, 2008. p.165-200.

5. Guven Y, Uysal O. The importance of student research projects in dental education. Eur $\mathbf{J}$ Dent Educ 2011;15(2) :90-7.

6. Hinton RJ, Dechow PC, Abdellatif H, Jones DL, McCann AL, Schneiderman ED, D'Souza R. Creating an evidence-based dentistry culture at Baylor College of Dentistry: the winds of change. J Dent Educ 2011; 75(3):279-90.

7. Brasil. Lei $n^{\circ}$ 10973. Dispõe sobre incentivos à inovação e à pesquisa científica e tecnológica no ambiente produtivo e dá outras providências. Brasília (DF): Congresso Nacional; 2004.

8. Buck Institute for Education. Aprendi-zagem Baseada em Projetos: Guia para professores de ensino fundamental e médio. 2 ed. Porto Alegre: Penso, 2008.

9. Sobral FR, Campos CJG. The use of active methodology in nursing care and teaching in national productions: an integrative review. Rev Esc Enferm USP 2012; 46(1):202-11. [Acesso em 03/10/2014]. Disponível em: http://www.scielo.br/pdf/reeusp/v46n1/en_v4 6n1a28.pdf

10. Varela Pinedo LF, Ortiz Saavedra PJ, Livia Segovia J. Actitudes de docentes y estudiantes de pregrado de medicina hacia la metodología activa de enseñanza- aprendizaje. Rev Med Hered 2009; 23(3):162-8. [Acesso em 03/10/2014]. Disponível em: http://www. scielo.org.pe /pdf/rmh/v20n3/v20n3ao7.pdf

11. Morin E. Educação e complexidade: os sete saberes e outros ensaios. São Paulo: Cortez, 2002.

Correspondência para:

José Renato Cavalcanti Queiroz

e-mail: joserenatocq@ hotmail.com

Curso de Odontologia da UnP

Av. Salgado Filho, 1610

59056-000 Natal, RN 